\title{
Temporal Processing Abilities of Adults with Tune Deafness
}

\author{
Keonseok Yoon', Nour Alsabbagh', Hyunsook Jang ${ }^{2}$ \\ 'Department of Speech Pathology and Audiology, Graduate School, Hallym University, Chuncheon, Korea \\ ${ }^{2}$ Division of Speech Pathology and Audiology, Research Institute of Audiology and Speech Pathology, \\ College of Natural Sciences, Hallym University, Chuncheon, Korea
}

\author{
음치 성인의 시간적 처리 능력 \\ 윤건석 ${ }^{1}$ Nour Alsabbagh ${ }^{1} \cdot$ 장현숙 $^{2}$
}

한림대학교 일반대학원 언어병리청각학과', 한림대학교 자연과학대학 언어청각학부 · 청각언어연구소 ${ }^{2}$

\begin{abstract}
Purpose: The purpose of the study was to investigate the temporal processing abilities in individuals with tune deafness. Methods: First, the scores of Distorted Tunes Test (DTT), which is a web-based tool for identifying tune-deaf individuals, were collected from 346 young adults. Second, Frequency Pattern Test (FPT), Duration Pattern Test (DPT), and Gaps-In-Noise (GIN) test were randomly conducted on the tune deafness group (TDG) and the control group (CG). TDG consisted of 13 young Korean adults who are self-reportedly amusic and performed $\leq 19$ scores on DTT. CG included 15 who are not self-reportedly amusic and performed $\geq 24$ scores on the same test. The scores of FPT, DPT, and GIN test were compared between TDG and CG. Results: The criterion for tune deafness in the lowest 10th percentile on DTT included the score up to 19. Mann Whitney U nonparametric analysis revealed significantly lower performances in both labeling $(p<0.05)$ and humming $(p<0.01)$ modes of FPT in TDG, but not in DPT. GIN thresholds in the two groups significantly differed following the paired $t$-test, revealing upper threshold in the right ear in TDG $(p<0.05)$, but represented performances within normal ranges. Conclusion: Pitch processing deficits followed by poor performances on FPT by TDG suggest that DPT may be a more appropriate clinical choice when assessing temporal processing abilities in tune-deaf population. High performance variables in terms of temporal processing abilities within TDG also suggest further scrutiny of temporal processing abilities in the affected population is necessary.
\end{abstract}

Key Words: Temporal processing ability, Tune deafness, Distorted Tunes Test.

Received: May 2, 2019 / Revised: June 5, 2019 / Accepted: June 6, 2019

Correspondence: Hyunsook Jang, Division of Speech Pathology and Audiology, Research Institute of Audiology and Speech Pathology, College of Natural Sciences, Hallym University, 1 Hallym Daehakgil, Chuncheon 24252, Korea Tel: +82-33-248-2218 / Fax: +82-33-248-3420 / E-mail: hsjang@hallym.ac.kr

\section{INTRODUCTION}

음치(congenital amusia)란 청력손실, 지능, 인지 능력, 음악 적 노출과는 별개로 나타나는 음악 지각에 대한 일생적인 손상 (Provost, 2011)으로 정의되며, 인구의 약 $1.5 \%$ (Peretz \& Vuvan, 2017)에서 4\% (Kalmus \& Fry, 1980; Sloboda et al., 2005) 의 출현율을 나타내는 신경발달적(neurodevelopmental) 장애 이다(Albouy et al., 2013; Tillmann et al., 2009). 음치는 유전

(c) This is an Open Access article distributed under the terms of the Creative Commons Attribution Non-Commercial License (https://creativecommons.org/licenses/by-nc/4.0) which permits unrestricted non-commercial use, distribution, and reproduction in any medium, provided the original work is properly cited.
적 특징을 나타내며(Drayna et al., 2001; Peretz et al., 2007), 유사한 음(tone)들을 변별하는 데 어려움을 보일 뿐만 아니라 (Braun et al., 2008), 자신 혹은 타인이 노래할 때 비정상적으 로 음정이 벗어남을 알아채지 못한다(Peretz \& Vuvan, 2017). 이러한 음악적 처리 능력의 결함에 대한 다수의 신경영상 (neuroimaging) 연구들은 청각 정보의 지각을 담당하는 대뇌 우반구의 청각피질(auditory cortex) 및 청각피질과 하전두회 (inferior frontal gyrus)의 연결로에 이상을 보고함으로써 음치 의 신경학적 결함을 증명하기도 하였다(Albouy et al., 2013; Hyde et al., 2006; Loui et al., 2009). 또한 정상의 말초청력 수 준에도 불구하고 음고(pitch) 처리적 결함(Tillmann et al., 2009) 
및 중추청각처리기관 내 청각생리적 결함(Braun et al., 2008) 이 보고됨에 따라 음치는 중추청각처리장애(central auditory processing disorder)인 것으로 보고되기도 하였다(Braun et al., 2008).

국내에선 아직 음치 선별의 기준에 대한 일치된 합의가 이루 어지지 않고 있으나, 국외에서는 일찍이 검사도구 개발 및 음악 적 능력 평가를 통해 음치 선별이 시도된 바 있다(Kalmus \& Fry, 1980). 현재 영어권에서 가장 많이 사용되는 웹 기반(webbased) 음치 선별 도구는 Distorted Tunes Test (DTT) (Drayna et al., 2001)와 Montreal Battery of Evaluation of Amusia (MBEA) (Peretz et al., 2003) 두 가지이다. 두 검사 도구가 지 향하는 음지각적 평가 요소는 서로 차이를 보이는데, MBEA는 음계(scale), 멜로디 흐름(contour), 음정 차이(interval), 리듬 (rhythm), 박자(meter), 기억(memory) 등 음악 처리 능력의 여 섯 가지 하위 항목에서의 음악적 처리 능력을 종합적으로 평가 하는 반면, DTT는 음고 인지 능력에 초점을 두어 평가한다는 점에서 서로 다르다. 위 검사들에서 기준으로 하고 있는 특정 점수에 미달될 경우 DTT와 MBEA 각 음치를 'tune deafness' 와 'congenital amusia'라 명명하는데, 일반적으로 음치를 의미 한다는 점에서 서로 특징적 관련이 있는 것으로 평가되어 같은 맥락에서의 용어 사용이 이루어지고 있다(Braun et al., 2008; Lense et al., 2013; Tillmann et al., 2009). 이 중 DTT는 음고 지각 능력의 결함을 판별하기 위한 도구로써 이상적이며(Drayna et al., 2001), 영어권 외 다문화적인 사용 가능성 또한 권고 된 바 있다(Drayna et al., 2001). 또한 낮은 DTT 점수와 낮은 음 정 산출 능력 간 높은 상관관계도 보고되어 음치를 판별함에 높 은 민감도를 나타낸다고 보고되기도 하였다(Lens et al., 2013). 더하여 DTT에 대한 음악(기악) 전문가와 비전문가의 뇌신경학 적 반응을 뇌혈류 기반 기능적 뇌기능 영상의 관찰을 통해 두 집단이 정상 말초청력 수준이지만 중추적 청각 처리에 차이가 있음이 보고된 바 있다(Seung et al., 2005).

앞선 음치의 중추청각기관의 결함이 보고됨에 따라 그들의 시간적 처리 능력(temporal processing ability)에 대한 관심을 받게 되었다. 시간적 처리 능력이란 제한되거나 정의된 시간 영 역 내에서의 소리 또는 변조된 소리의 지각으로 정의되며 (Musiek et al., 2005), 시간적 순서화(ordering), 시간적 분석 (resolution), 시간적 통합(intergration) 및 시간적 차폐(masking) 등의 네 가지 하위 능력을 포함한다. 위 영역 중 시간적 처 리 능력을 알아보기 위해 임상적으로 사용되는 검사는 시간적 순서화 능력 영역의 Frequency Pattern Test (FPT)와 Duration Pattern Test (DPT) 두 가지 검사이며, 시간적 분석의 영역에서 는 Gaps-In-Noise (GIN) test가 널리 사용된다. 위 검사들은 임상적으로 높은 신뢰도와 타당도가 검증되었으며(Musiek,
1994; Musiek et al., 2005), 검사 자극이 비언어적인 특성을 가 지므로 중추청각처리장애 진단을 위한 행동검사로써 임상에서 널리 쓰이고 있다. 시간적 처리 능력은 비구어적인 정보의 처리 를 담당하는 우반구와 구어적 자극의 처리를 담당하는 좌반구 간의 독립적, 상호적 기능의 온전함을 요구하므로, 측두엽 및 반구 간 정보 교환 능력을 알아보는 데 유용한 정보를 제공 (Musiek, 1994)할 뿐만 아니라 말소리와 음악 지각에 중요한 역 할을 담당한다.

음치 성인을 대상으로 그들의 시간적 처리 능력을 알아본 이 전의 선행연구들은 모두 대조군과 비교 시 낮은 수행력을 보고 하고 있다(Ishii et al., 2006; Jones et al., 2009). Ishii et al. (2006)은 18 55세 연령 범위의 전문 가수 15 명과 노래할 때 음 정이 맞지 않는 대상자 63명을 대상으로 구어반응 조건에서 FPT와 Random Gap Detection Test (RGDT) (Keith, 2000) 수행력을 비교하였으며, 연구 결과 FPT에서 그룹 간 유의미한 차이를 보고하였으나, RGDT 검사에서는 통계적 차이가 없음 을 보고하였다. Jones et al.(2009)은 DTT에서 18점 이하의 수 행력을 나타내었으며, 15 60세 연령 범위의 음치(tune deafness) 성인 35명과 24점 이상을 나타낸 대조군 34명을 대상으로 $\mathrm{FPT}, \mathrm{DPT}, \mathrm{GIN}$ 검사 수행력을 비교한 결과, 모든 검사 수행력 에서 그룹 간 유의미한 차이를 보고하였지만, GIN 검사에서는 두 그룹 수행력 모두 정상 범위에 나타남을 보고하였다. 앞선 선행연구들의 검사를 종합하여 볼 때, 음치의 시간적 분석 능 력에는 문제가 없으나 시간적 순서화 능력에는 결함이 있음을 시사하나 이러한 결론을 수렴하기에는 다음 두 가지 사항에 대 한 검증이 시도될 필요가 있다. 첫째, 노화가 시간적 처리 능력의 감소를 야기한다는 연구결과를 고려하였을 때(Bellis \& Wilber, 2001; Jang et al., 2008), 위 연구들 모두 노화변인(aging variable) 통제가 이루어지지 않아 음치의 시간적 처리 능력에 대한 명확한 정보를 제공하는 데 제한이 있다. 이는 노화 변인을 배 제한 음치 성인의 시간적 처리 능력에 대한 연구 자료가 필요함 을 시사한다. 둘째, 시간적 순서화 검사에서 피검자의 반응 방 법 또한 대뇌반구의 독립적, 상호적인 청각적 처리 능력에 대한 구체적인 정보를 제시하지 않아 그들의 시간적 처리 능력의 깊 이 있는 해석에 다소 제한이 있다. Ishii et al.(2006) 연구의 $\mathrm{FPT}$ 에서 반구 간 전이 능력에만 초점을 둔 구어 방식의 피검 자 반응 형식을 사용하였으며, Jones et al.(2009)의 연구에서는 FPT의 제시음을 실제 임상에서 사용하는 $880 \mathrm{~Hz}$ 와 $1,122 \mathrm{~Hz}$ 가 아닌 $880 \mathrm{~Hz}$ 와 $1,430 \mathrm{~Hz}$ 를 사용하였다. 그러므로 노화 변 인을 배제한 음치 성인을 대상으로 임상적 타당도와 신뢰도가 검증된 검사도구의 파라미터를 사용하여 음치의 중추청각 처 리 특성을 살펴볼 필요가 있다.

음치와 관련된 시간적 처리 능력 결함을 측정하기 위해서 음 
치 대상자의 선별이 선결되어야 하는데 국내에서 일반적으로 시행되는 음치 선별은 설문지나 평가자의 주관적인 관찰에 의 존하고 있어 객관적인 선별 도구의 필요성이 강조되고 있다 (Hwang, 2008; Kown, 2007; Son, 2003). 본 연구는 다문화권 사용이 권장된 웹 기반 음치 선별 도구 DTT로 선별된 음치 성 인을 대상으로 시간적 순서화 및 분석 능력을 살펴봄으로써 임 상적 시사점을 도출하는 데 그 목적이 있다.

\section{MATERIALS AND METHODS}

\section{연구 대상}

인터넷 커뮤니티 내 연구 참여 모집 공고를 통해 본인 스스로 참여 의사를 밝히고 연구 참여에 동의한 전국의 20대(평균연령 $22.9 \pm$ 2.06세, 연령 범위 20 29세) 성인 346명(남: 121명, 여: 225명)을 대상으로 하였다. 이후 DTT 수행력에 따라 선별된 음치 성인의 시간적 처리 능력을 살펴보기 위해 음치 그룹(tune deafness group, TDG)과 정상 대조군(control group, $\mathrm{CG}$ )으로 나누어 진행하였다. TDG는 자가로 음치를 보고하고 DTT에서 하위 $10 \%$ (Jones et al., 2009)의 수행력을 보인 인원 중 연구 참 여를 원하는 13명[남: 5명, 여: 8명, 평균연령: 23.85( \pm 2.79$)]$ 을 대상으로 하였다. TDG의 DTT 평균과 표준편차는 $15.69 \pm$ 2.72점, 범위는 8 19점이었다. $\mathrm{CG}$ 는 음치에 대한 자가보고가 없고 DTT에서 24점 이상을 보인(Jones et al., 2009) 15명[남: 7 명, 여: 8명, 평균연령: 22.40( \pm 2.85)을 대상으로 하였다. 모든 연구 참여 피검자는 첫째, 소음 수준이 $40 \mathrm{dBA}$ 이하인 방음실 (SDW-450, Hearing Medics, Seoul, Korea)에서 TDH-50 Headphone (model 296 D260-2, Telephonics, Farmingdale, NY, USA)을 사용한 순음청력검사(GSI 61, Grason-Stadler Inc., Eden Prairie, MN, USA) 결과 양이 모두 250 8,000 Hz 에서 $20 \mathrm{~dB}$ HL 이하의 정상 청력(ANSI, 1996)을 보이고, 둘째, 어음인지도검사 결과 양이 모두 $92 \%$ 이상의 수행력을 나타내 고, 셋째, 고막운동도검사(GSI TympStar, Grason-Stadler) 결과
양이 모두 Type A를 보이고, 넷째, 손잡이 설문지(Kang, 1994) 를 통해 오른손잡이임이 확인되고, 다섯째, 과거 이과적, 신경학 적 병력이 보고되지 않은 대상만을 연구에 포함하였다(Table 1).

\section{연구 절차}

본 연구는 음고 인지 능력을 평가하는 웹 기반 DTT를 통해 점수를 수집하였다. 모든 피검자는 진행 방법에 관한 설명을 충분히 숙지한 후 검사에 참여하였다. 피검자는 제시된 모든 검 사음에 집중할 수 있도록 소음이 없는 조용한 방에서 노트북 (HP Pavilion dv2500se, HP Inc., Palo Alto, CA, USA)의 내 장 스피커를 통해 본인이 편안하게 느끼는 강도의 소리 크기에 서 진행하였으며, 검사음을 모두 들은 후 반응하도록 하였다. 연 구에 참여한 모든 피검자들에게 시간적 처리 능력을 알아보는 검사인 $\mathrm{FPT}, \mathrm{DPT}, \mathrm{GIN}$ 검사를 무작위 순서로 실시하였으며, 방음실에서 GSI 61 을 통해 $\mathrm{CD}$ 검사음원을 $\mathrm{TDH}-50$ 헤드폰으 로 자극음을 들려준 후 반응하도록 하였다. 모든 검사에 앞서 피검자에게 검사 진행 방법에 대한 구어적 설명 및 연습문항을 통해 본 검사 전 충분히 연습할 수 있도록 하였다. 피검자의 요 청 시 충분한 휴식을 제공하였고, $1,000 \mathrm{~Hz}$ 의 보정음을 통해 검 사음원에 대한 보정을 실시한 뒤 귀별 순음역치평균 $(500,1,000$, $2,000 \mathrm{~Hz}$ average)의 $50 \mathrm{~dB}$ SL 강도에서 제시하였다.

\section{Distorted Tunes Test (DTT)}

DTT는 음고 인지 능력에 초점을 두어 개인의 음악적 능력을 평가하는 웹 기반 검사로 한 개의 연습문항을 포함한 총 27개 의 짧은 멜로디를 듣고 정확히 연주되었는지의 여부를 예, 아니 오로 반응하는 형식의 검사이다(Figure 1). 검사문항의 구성은 연주되는 음의 비정상적인 이탈 없이 정확하게 연주되는 9 개의 멜로디와 간헐적으로 반음(semi-tune)이 변조된 음을 포함하 는 멜로디 17 개로 구성된다(변조 범위: 반음 기준 $-2 \sim+2$ ). 검사 소요 시간은 약 10 분 정도이며, 점수 범위는 0 점에서 26점까지 이다. 모든 문항에 응답 후 결과 화면을 통해 최종 점수가 화면

Table 1. Hearing information of the participants $(n=346)$

\begin{tabular}{|c|c|c|c|c|c|c|c|c|c|}
\hline \multirow{2}{*}{ Group } & \multirow{2}{*}{ Ear } & \multicolumn{6}{|c|}{ Threshold (dB HL) } & \multirow{2}{*}{ PTA (dB HL)* } & \multirow{2}{*}{ WRS (\%) } \\
\hline & & $250 \mathrm{~Hz}$ & $500 \mathrm{~Hz}$ & $1,000 \mathrm{~Hz}$ & $2,000 \mathrm{~Hz}$ & $4,000 \mathrm{~Hz}$ & $8,000 \mathrm{~Hz}$ & & \\
\hline \multirow[t]{2}{*}{$\overline{\mathrm{CG}}$} & Rt & $-6.70(9.00)$ & $-6.70(8.80)$ & $1.67(8.80)$ & $4.00(2.80)$ & $11.70(6.17)$ & $3.00(7.51)$ & $-0.20(5.45)$ & $100.00(0.00)$ \\
\hline & $\mathrm{Lt}$ & $-6.70(8.80)$ & $-7.70(6.78)$ & $2.67(9.80)$ & $2.00(4.93)$ & $5.67(5.63)$ & $5.00(6.81)$ & $-1.10(4.82)$ & $100.00(0.00)$ \\
\hline \multirow[t]{2}{*}{ TDG } & Rt & $-4.60(8.03)$ & $-6.50(8.99)$ & $2.69(9.49)$ & $5.77(4.00)$ & $13.10(4.80)$ & $6.92(8.55)$ & $0.23(4.85)$ & $99.69(1.11)$ \\
\hline & $\mathrm{Lt}$ & $-4.20(9.76)$ & $-6.20(7.40)$ & $2.69(9.71)$ & $3.85(6.50)$ & $8.46(6.58)$ & $6.15(6.18)$ & $-0.40(5.20)$ & $99.38(1.50)$ \\
\hline \multirow[t]{2}{*}{ Overall } & Rt & $-5.70(8.47)$ & $-6.60(8.72)$ & $2.14(8.97)$ & $4.82(3.46)$ & $12.30(5.52)$ & $4.82(8.11)$ & $0.00(5.09)$ & $99.86(0.76)$ \\
\hline & $\mathrm{Lt}$ & $-5.50(9.16)$ & $-7.00(6.98)$ & $2.68(9.57)$ & $2.86(5.68)$ & $6.96(6.14)$ & $5.54(6.43)$ & $-0.80(4.92)$ & $99.71(1.05)$ \\
\hline
\end{tabular}

Mean pure-tone threshold levels (standard diviations) for TDG and CG, right and left ears. *Average pure tone thresholds (PTA) for 500, 1,000, and 2,000 Hz. PTA: pure tone average, WRS: word recognition score, CG: control group, TDG: tune deafness group, Rt: right ear, Lt: left ear 


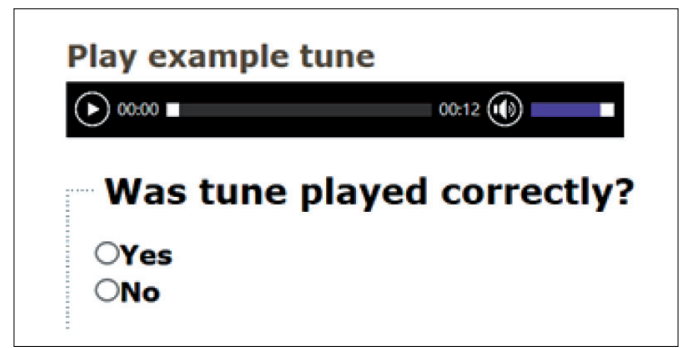

Figure 1. Test image of Distorted Tunes Test.

에 나타난다.

\section{주파수패턴검사(FPT)}

시간적 순서 능력을 평가하는 FPT (Musiek, 1994)는 한쪽 귀 에 제시된 높낮이가 다른 두 개의 순음 $(880,1,122 \mathrm{~Hz})$ 을 듣고 '높고, 낮고'와 같이 구어로 반응하는 방식과 들은 음을 따라하 는 허밍 반응 방식을 요청하는 검사이다. 검사음은 '고고저, 저 저고, 고저고, 저고저, 저고고, 고저저' 등 총 6개의 높낮이 패턴 으로 구성되어 있으며, 목록당 15 문제씩 총 4 목록으로 구성되 어 있다. 제시된 모든 음의 길이는 $150 \mathrm{msec}$, 검사문항 사이의 제시 간격은 $600 \mathrm{msec}$, rise-fall time은 $10 \mathrm{msec}$ 이다. FPT는 측두엽 및 반구 간 정보 교환에 높은 민감도와 특이도를 나타 낸다(Musiek, 1994). FPT의 경우 각 귀에 구어 및 허밍 반응을 요청하였으며, 훈련된 검사자가 피검자의 반응을 듣고 채점하 였다. 또한 점수 산정 방법은 귀별 구어 반응과 허밍 반응 각 15 점을 만점으로 하여 백분율(\%)로 환산하여 계산하였으며, 들린 음의 높낮이가 불확실함을 느낄 경우 추측하여 반응하도 록 하였다.

\section{음길이패턴검사(DPT)}

시간적 순서 능력을 평가하는 DPT (Musiek, 1994)는 한쪽 귀에 길이가 다른 $1,000 \mathrm{~Hz}$ 지속음을 듣고 '길고, 짧고'와 같이 구어로 반응하는 방식과 들은 음을 따라하는 허밍 반응 방식 을 요청하는 검사이다. 검사음은 '장장단, 장단장, 장단단, 단장 단, 단장장, 단단장'으로 구성된 총 6 개의 음길이 패턴으로 구성 되어 있으며, 목록당 15 문제씩 총 4 목록으로 구성되어 있다. 제

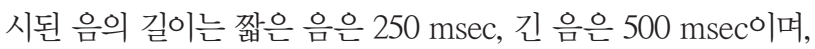
rise-fall time은 $10 \mathrm{msec}$, 검사문항 사이 간격은 $600 \mathrm{msec}$ 이 다. DPT는 측두엽 및 반구 간 정보 교환에 높은 민감도와 특이 도를 나타낸다(Musiek, 1994). DPT의 경우 각 귀에 구어 및 허 밍 반응을 요청하였으며, 훈련된 검사자가 피검자의 반응을 듣 고 채점하였다. 또한 점수 산정 방법은 귀별 구어 반응과 허밍 반응 각 15점을 만점으로 하여 백분율(\%)로 환산하여 계산하 였으며, 들린 음의 장단이 불확실함을 느낄 경우 추측하여 반 응하도록 하였다.

\section{GIN 검사}

시간적 분석 능력을 평가하는 GIN 검사(Musiek et al., 2005) 는 6초간 제시되는 백색잡음(white noise) 내에서 0 3번까지 무작위로 제시되는 간격(gap)이 탐지될 때마다 버튼을 눌러 반 응하도록 요청받는 검사이다. 10 개의 검사문항으로 구성된 한 개의 연습문항 목록과, 최대 36 개의 검사문항으로 구성된 네 개의 검사 목록으로 구성된다. 연습 목록은 $5,8,10,15,20$ $\mathrm{msec}$ 의 간격이 검사음 내 무작위로 총 네 번씩 제시되며, 검사 목록은 2, 3, 4, 5, 6, 8, 10, 12, 15, $20 \mathrm{msec}$ 의 간격이 무작위로 총 여섯 번씩 제시된다. GIN 검사는 대뇌병변에 $67 \%$ 의 민감도 와 $94 \%$ 의 특이도를 보이며, 정상 gap 역치의 범위는 $5 \sim 6 \mathrm{msec}$ 인 것으로 보고되었다(Musiek et al., 2005). GIN 검사의 경우 양 귀에 독립적으로 검사를 진행하였으며, 점수 산정 방법의 경 우 귀별 점수 수행력은 목록당 총 60 번 제공되는 gap 중 탐지 한 gap을 합산하여 백분율로 계산하였으며, 역치는 제시되는 6 번의 간격 중 4 번 이상 탐지하는 간격을 각 귀의 역치로 산정하 였다. 또한 목록당 총 제시되는 60 개의 간격 중 정반응한 횟수 를 계산한 뒤 백분율(\%)로 환산하였다.

\section{통계 분석}

본 연구의 결과는 SPSS version 23.0 (IBM Corp., Armonk, NY, USA) 프로그램을 사용하여 통계 분석하였다. DTT의 경 우 전국의 20대 성인 346명의 점수 분포를 알아보았으며, 하위 $10 \%$ (Jones et al., 2009)에 해당하는 19점 이하의 인원을 백분 율로 계산하여 한국인의 음치 출현율을 계산하였다. 시간적 처 리 검사의 경우 각 검사에 대한 그룹 내 귀별 수행력에 대한 기 술 통계 분석을 통해 평균과 표준편차를 구하였으며, 각 검사별 조건 간 차이를 보기 위해 통계 분석을 실시하였다. FPT, DPT 에서 그룹 내 반응 조건(허밍/구어)과 귀(오른쪽/왼쪽)에 따라 수행력 간 차이가 있는지 확인하기 위해 반복측정 이원분산분 석(repeated two-way ANOVA)을 실시하였으며, 분산 분석 결 과 구형성 검정이 기각될 경우 Greenhouse-Geisser 검정을 통 해 수정된 자유도와 $\mathrm{F}$ 값을 보고하였다. 각 반응 조건과 귀에 따 라 그룹 간 차이를 확인하기 위해 독립표본 $t$ 검정을 실시하였다. 추가로 반응 조건별 그룹 간 수행력 비교를 위해 Mann Whitney $\mathrm{U}$ Test 비모수검정을 실시하였다. GIN 검사의 백분율과 역치에 대한 귀별 그룹 간, 그룹별 귀 간 비교를 위하여 $t$ 검정을 실시하 였다. 모든 통계 분석은 유의수준 0.05 를 기준으로 하였다.

\section{RESULTS}

\section{$\mathrm{DTT}$ 의 분포}

Figure 2는 20대 성인 총 346 명의 DTT의 점수 분포를 그래 
프로 나타낸 결과이다. 점수 범위는 8 26점으로 나타났다. 8점 의 1명을 제외하고 0 11점에 속하는 인원은 없었으며, 12점에 서 18 점에는 각각 10 명 이하의 인원이었고, 19 점과 20점이 각 14명이었으며, 21점부터 26점에는 각 31명에서 최대 69명이 분 포하였다. Jones et al.(2009) 연구에서 음치로 규정한 18점 이 하(하위 $10 \%)$ 의 기준을 본 연구결과에 적용하였을 때 18 점 이 하는 29명 (8.38\%)으로 나타났다. 또한 본 연구에서 하위 $10 \%(34.6$ 명)의 지점은 19점인 것으로 나타났다.

\section{FPT 수행력 비교}

FPT 결과(Figure 3), 그룹별로 반응 조건과 귀별 수행력 평 균과 표준편차는 $\mathrm{CG}$ 에서 허밍 조건의 경우 오른쪽 $97.28 \pm$ $6.98 \%$, 왼쪽 $98.67 \pm 5.16 \%$ 로 나타났으며, 구어 조건의 경우 오른쪽 $94.22 \pm 12.05 \%$, 왼쪽 $93.76 \pm 12.72 \%$ 로 나타났다.
$\mathrm{TDG}$ 에서는 허밍 조건의 경우 오른쪽 $81.54 \pm 31.17 \%$, 왼쪽 $81.03 \pm 35.78 \%$ 로 나타났으며, 구어 조건의 경우 오른쪽 61.03 $\pm 33.87 \%$, 왼쪽 $61.03 \pm 31.95 \%$ 로 나타났다.

그룹별 FPT 수행력에 대한 반복측정 이원분산분석을 실시 한 결과(Figure 3), $\mathrm{CG}$ 의 경우 반응 조건과 귀[F(1,14) = 0.376, $p=0.550]$ 의 상호작용은 유의하지 않았으며, 귀[F(1, 14) = $0.027, p=0.872]$ 와 반응 조건 $[\mathrm{F}(1,14)=4.354, p=0.056]$ 의 주 효과도 유의하지 않았다. 반면 TDG의 경우 반응 조건과 귀 $[\mathrm{F}(1,12)=0.004, p=0.948]$ 의 상호작용은 유의하지 않았으며, 귀[F(1,12) $=0.006, p=0.941]$ 의 주 효과도 유의하지 않았으나, 반응 조건 $[\mathrm{F}(1,12)=18.292, p=0.001]$ 의 주 효과는 유의하였다. 각 반응 조건과 귀에 따른 그룹 간 $\mathrm{FPT}$ 점수를 통계 분석한 결 과, 허밍 조건에서는 차이를 보이지 않았으나 $(p<0.05)$ 구어 조 건에서 CG보다 TDG의 수행력이 유의하게 낮음을 확인하였다.

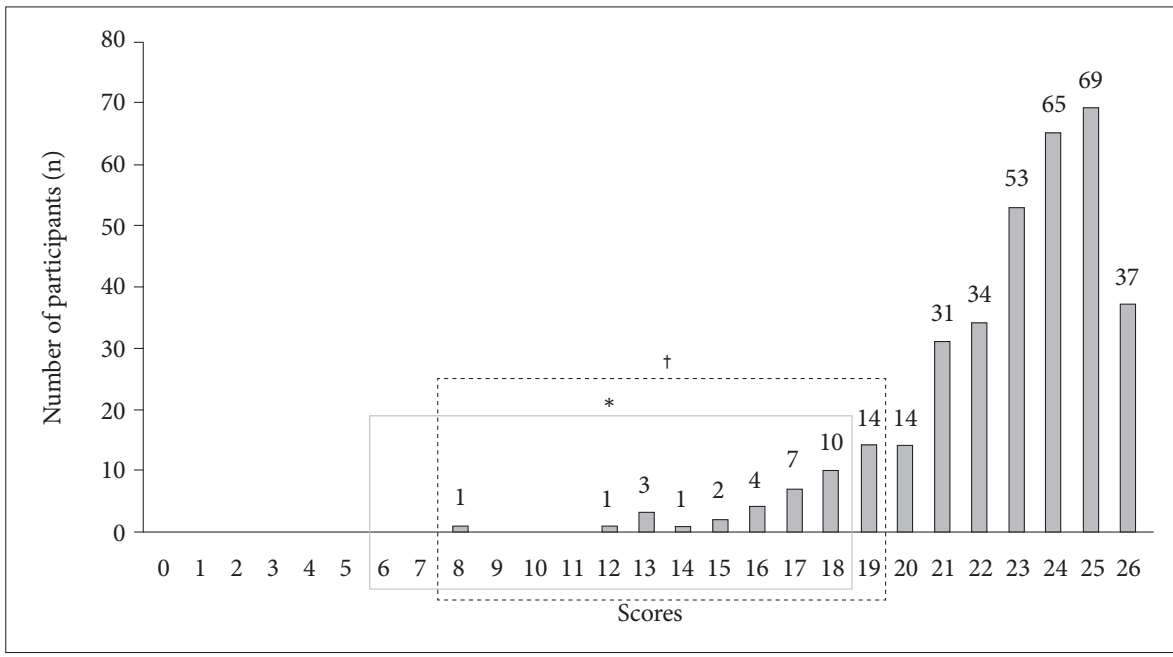

Figure 2. Distribution of scores on Distorted Tunes Test $(n=346)$. *Individuals with tune deafness in the 10th lowest percentile (Adapted from Jones et al. Ear and Hearing 2009;30:63-72.), 'Individuals with tune deafness in the 10th lowest percentile in this study.
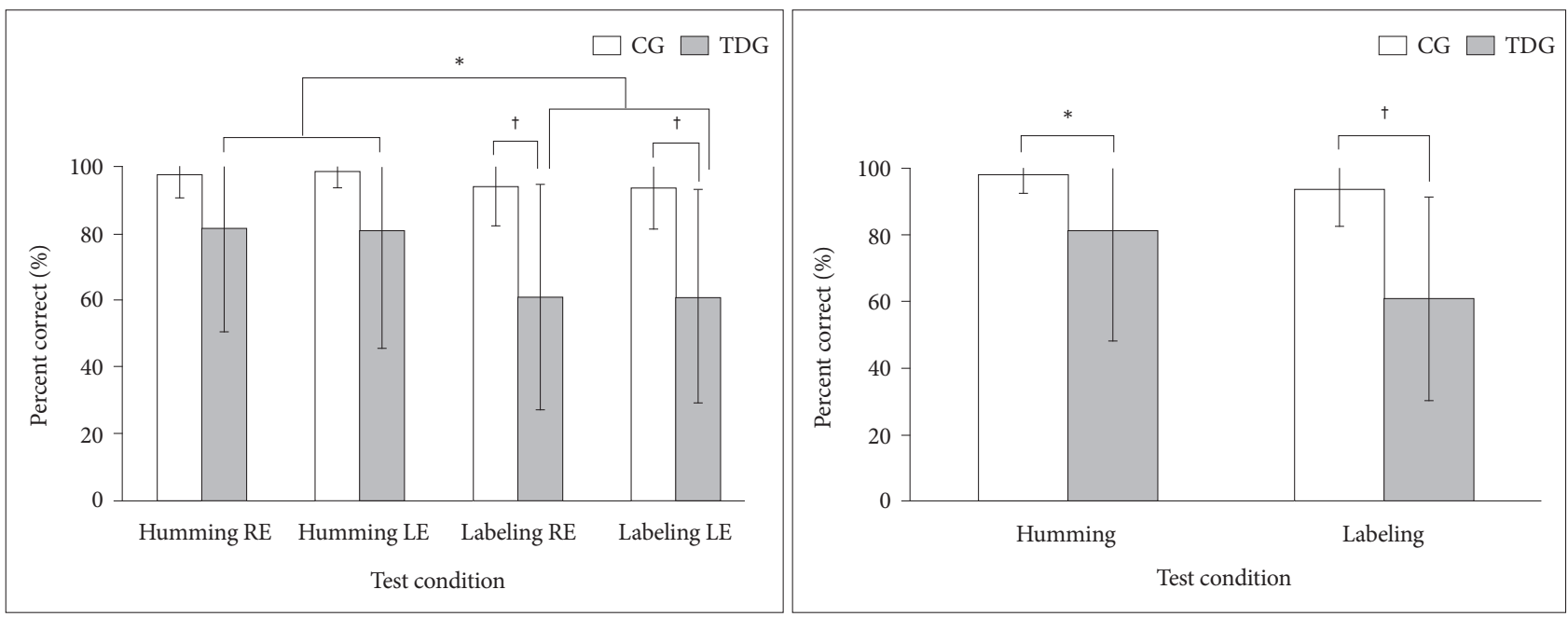

Figure 3. Comparison of group performances in Frequency Pattern Test for both humming and labeling modes. Note that left and right panels indicate separate and combined ear performances, respectively. ${ }^{*} p<0.05,{ }^{\dagger} p<0.01$. CG: control group, TDG: tune deafness group, RE: right ear, LE: left ear. 
각 그룹의 반응 조건별 귀 간 차이를 보이지 않았으므로 양이 수행력을 합산한 후, 반응 조건에 따른 그룹 간 수행력 차이를 Mann Whitney 비모수검정을 실시하여 확인한 결과(Figure $3)$, 그룹 간 허밍 $(p<0.05)$ 과 구어 조건 $(p<0.01)$ 모두 TDG 의 수행력이 $\mathrm{CG}$ 의 수행력보다 유의하게 낮았다.

\section{DPT 수행력 비교}

DPT 결과(Figure 4), 반응 조건에 따른 그룹별 귀별 수행력 평균은 $\mathrm{CG}$ 에서 허밍 조건의 경우 오른쪽 $94.67 \pm 9.50 \%$, 왼쪽 $91.56 \pm 14.13 \%$ 로 나타났으며, 구어 조건의 경우 오른쪽 92.44 $\pm 13.77 \%$, 왼쪽 $92.89 \pm 11.67 \%$ 로 나타났다. TDG에서는 허 밍 조건의 경우 오른쪽 $83.08 \pm 21.19 \%$, 왼쪽 $85.64 \pm 19.41 \%$ 로 나타났으며, 구어 조건의 경우 오른쪽 $83.59 \pm 21.88 \%$, 왼 쪽 $86.15 \pm 23.17 \%$ 로 나타났다.

그룹별 $\mathrm{DPT}$ 수행력에 대한 반복측정 이원분산분석을 실시 한 결과(Figure 4), CG의 경우 반응 조건과 귀 $[\mathrm{F}(1,14)=1.584$, $p=0.229]$ 의 상호작용은 유의하지 않았으며, 귀 $[\mathrm{F}(1,14)=$ $4.425, p=0.054]$ 와 반응 조건 $[\mathrm{F}(1,14)=0.146, p=0.709]$ 의 주 효과도 유의하지 않았다. TDG의 경우도 반응 조건과 귀[F(1, 12) $=0.000, p=1.000]$ 의 상호작용, 귀 $[\mathrm{F}(1,12)=1.071, p=$ $0.321]$ 와 반응 조건 $[\mathrm{F}(1,12)=0.016, p=0.901]$ 의 주 효과 모두 유의하지 않았다. 각 그룹의 반응 조건별 귀 간 차이를 보이지 않았으므로 양이 수행력을 합산한 후, 반응 조건에 따른 그룹 간 수행력 차이를 반응 조건별 Mann Whitney U 비모수검정을 통 해 확인한 결과, 그룹 간 허밍 $(p>0.05)$ 과 구어 조건 $(p>0.05)$ 모두 유의미한 차이를 보이지 않았다.

\section{GIN 검사 수행력 비교}

$\mathrm{GIN}$ 검사에서 반응 점수를 합산한 결과(Figure 5), 평균 백 분율 점수의 경우 $\mathrm{CG}$ 의 오른쪽 수행력은 $69.22 \pm 8.63 \%$, 왼 쪽은 $71.33 \pm 7.80 \%$ 로 나타났으며, TDG의 경우 오른쪽 65.38 $\pm 6.02 \%$, 왼쪽 $67.56 \pm 7.41 \%$ 로 나타났다. 평균 역치의 경우

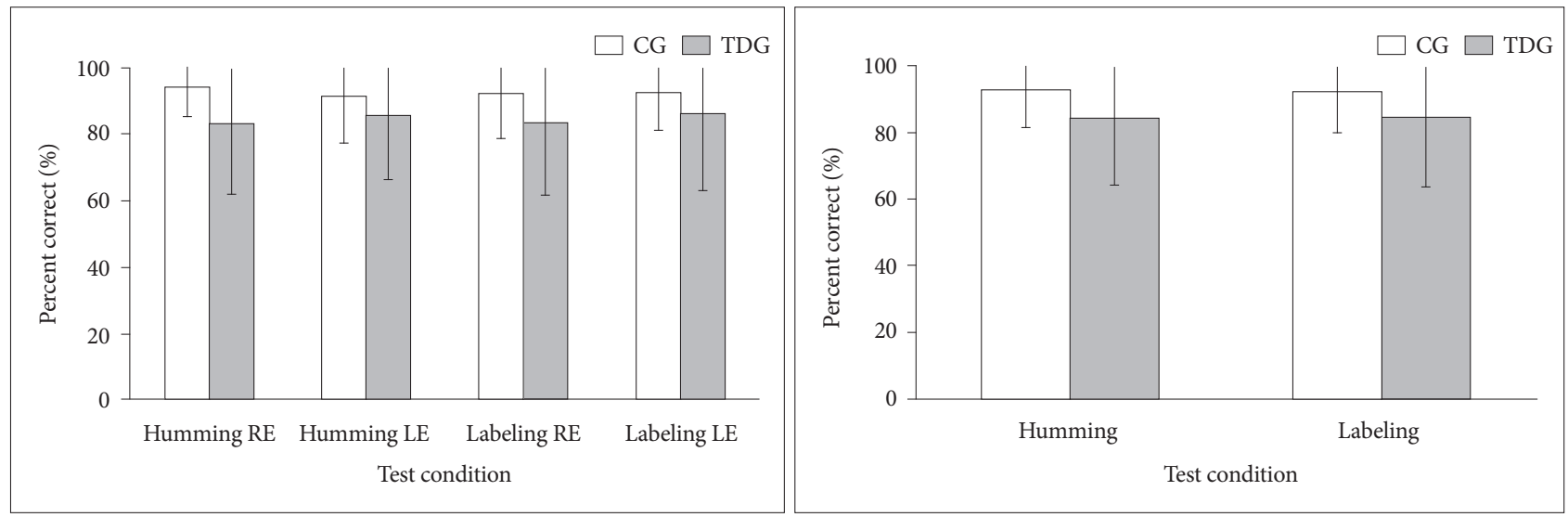

Figure 4. Comparison of group performances in Duration Pattern Test for both humming and labeling modes. Note that left and right panels indicate separate and combined ear performances, respectively. CG: control group, TDG: tune deafness group, RE: right ear, LE: left ear.

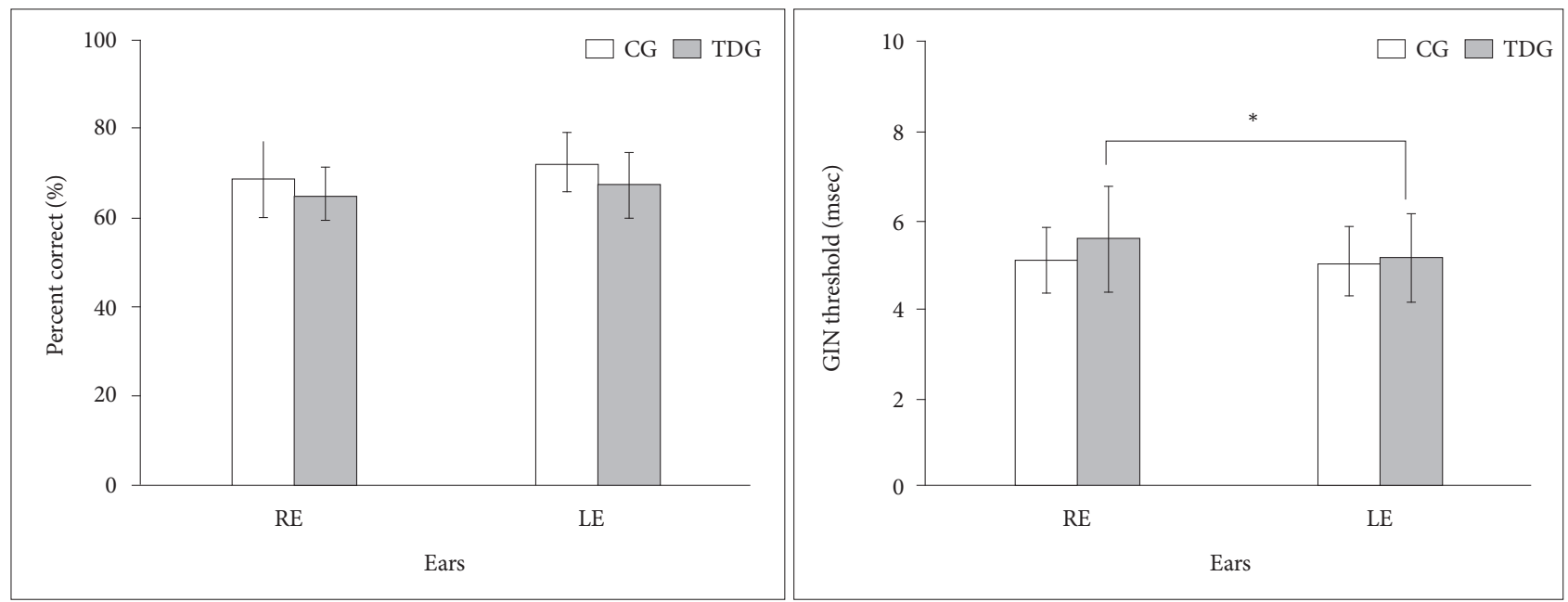

Figure 5. Comparison of group performances in GIN test. The left-sided figure represents percent correct scores and right-sided one represents GIN thresholds. * $p<0.05$. GIN: Gaps-In-Noise, CG: control group, TDG: tune deafness group, RE: right ear, LE: left ear. 
$\mathrm{CG}$ 는 오른쪽 $5.13 \pm 0.74 \mathrm{msec}$, 왼쪽 $5.07 \pm 0.80 \mathrm{msec}$ 로 나 타났으며, TDG의 경우 오른쪽 $5.62 \pm 1.19 \mathrm{msec}$, 왼쪽 $5.15 \pm$ $0.99 \mathrm{msec}$ 로 나타났다.

백분율과 역치 점수에 대한 귀별 그룹 간 점수 차이를 알아보 기 위해 독립표본 $t$ 검정을 각각 실시한 결과(Figure 5), 그룹 간 차이가 모두 유의하지 않았다 $(p>0.05)$. 백분율과 역치 점수에 대한 그룹별 귀 간 차이를 알아보기 위해 각각 대응표본 $t$ 검정 을 실시한 결과(Figure 5), CG는 모두 유의한 차이를 보이지 않았으며 $(p>0.05), \mathrm{TDG}$ 의 경우 백분율 점수에서는 유의한 차이를 보이지 않았으나 $(p>0.05)$, 역치 점수에서 오른쪽 귀의 역치가 왼쪽에 비해 유의미하게 높게 나타났다 $(p<0.05)$.

\section{DISCUSSIONS}

본 연구는 한국인을 대상으로 DTT를 실시하고, 그 검사 결 과를 바탕으로 선별된 음치 성인의 시간적 순서화 및 분석 능 력을 알아보고자 FPT, DPT 및 GIN 검사를 실시하였으며 그 결과를 정상 대조군과 비교하였다.

전국의 20대 성인 346명을 대상으로 DTT의 점수 분포를 살 펴본 결과 기존의 선행연구(Jones et al., 2009)에서 제시한 하 위 $10 \%$ 의 음치를 기준으로 하였을 때 18점 이하의 인원은 총 346 명 중 29명(8.38\%)이었으며, 본 연구에서의 하위 $10 \%$ 에 해 당하는 인원은 34.6명(19점)으로 1점 더 높게 나타났다. 먼저 18 점을 기준으로 하였을 때의 본 연구와 선행연구 간 출현율 차이를 살펴보면 Jones et al.(2009)의 연구에서는 무작위 865 명(연령 범위 15 60세)을 대상으로 점수 분포의 하위 10\%(18 점 이하)에 해당하는 인원을 음치로 정하였는데, 본 연구에서 18점 이하를 기준으로 하였을 때 기존의 선행연구와 유사한 수 치를 나타내었음을 확인하였다. 본 연구와 선행연구 간 약 $1.6 \%$ 의 차이는 넓은 연령 범위(17 54세)를 포함한 선행연구와 20 29세의 피검자를 포함한 본 연구의 대상자 간 연령 차이로 기인한 것으로 해석될 수 있다. 이전의 연구들은 개인의 시간적 처리 능력이 노화변인에 의해 감소됨을 입증하였다(Bellis \& Willber, 2001; Jang et al., 2008). 먼저 영어권의 피검자를 대 상으로 한 경우 Bellis \& Wilber(2001)는 연령대별 네 그룹 (20 25세, 35 40세, 55 60세, 70 75세의 연령 범위)으로 나누 어 $\mathrm{FPT}$ 수행력을 알아본 결과, 네 그룹 모두 허밍 조건에서 95\% 이상의 수행력을 나타내어 그룹 간 유의미한 수행력 차이 는 없었으나, 55 60세와 70 75세 연령대 두 그룹의 경우 95\% 이상의 허밍 조건 수행력과는 달리 나머지 그룹과의 구어 조건 에서 유의미하게 낮은 수행력(85\%)을 나타내어, 노화로 인한 시 간적 순서화 능력의 감소를 보고하였다. 국내에서 또한 연구가 진행된 바 있는데 Jang et al.(2008)은 20 29세(평균연령 21.2세)
의 성인과 60 70세(평균연령 63.7세)의 노인 10명을 대상으로 $\mathrm{FPT}$ 를 진행하였다. 그 결과 20대의 성인 그룹에서 높은 허밍 (양측 귀 99\%)과 구어 조건(우측 93\%, 좌측 94\%) 수행력 및 귀 간 유의미한 차이가 나타나지 않았으나 노인 그룹에서는 허밍 조건의 수행력(우측 79\%, 좌측 80\%)보다 구어 조건(우측 47\%, 좌측 44\%)에서 유의미하게 낮은 수행력을 나타내어 우반구 청 각피질 및 반구 간 전이 능력에 노화의 영향이 반영되었다고 보고하였다. 다시 말해 이는 노화변인이 시간적 순서 능력의 감 소를 야기할 수 있음을 나타내며, 실질적으로 감소된 처리 능력 이 결과적으로 검사문항에서 요구하는 음고 판별 능력에 영향 을 주었을 가능성이 있다. 하위 $10 \%$ 의 기준을 적용하였을 때 나타난 음치 여부의 선정점수는 선행연구보다 1점 더 높은 19 점까지를 포함하는 것으로 나타났는데, 이 또한 노화변인을 배 제한 20대 성인을 대상으로 하였을 때 나타난 수행 능력의 증 가로부터 기인된 것으로 해석될 수 있다. 그러나 DTT의 참여자 수를 비교하였을 때 선행연구(Jones et al., 2009) 864명과 본 연구의 346 명의 양적인 차이 또한 해당 점수 차이의 해석에 대 하여 추가적으로 고려해야 할 것이다.

본 연구에 참여한 346명 중 음치라고 자가보고한 인원은 총 81명(23.41\%)이었다. 18점 이하의 수행력을 나타낸 인원 29명 중 자가로 음치를 보고한 인원은 25명(86.21\%)이었으며 19점 이상의 수행력을 나타낸 인원 317명 중 음치가 아니라고 보고 한 인원은 261명(82.33\%)으로 DDT는 음치 여부에 대한 높은 신뢰도를 나타내었다. 그러나 19점 이상의 수행력을 보인 인원 중 자신이 음치라고 보고한 인원 수도 56명인 것으로 나타났을 뿐만 아니라 점수의 범위 또한 19 25점까지 다양함을 보였다. 이러한 차이는 DTT가 음고 인지 능력에 초점을 두어 멜로디 흐름, 간격, 리듬, 박자, 기억을 포함하는 다른 음악적 처리 능력 (Peretz et al., 2003)을 반영하지 않음으로써 좀 더 포괄적인 개 념의 음치 진단에 제한적일 수 있음을 시사한다. 이와 동시에 연구 참여자들이 보고한 음치의 여부는 본인의 주관이 반영된 가능성을 배제할 수 없을 뿐더러, 현재 국내에서 본인 스스로 음치라 규명하기 위한 보다 객관적인 기준이 모호한 실정이므 로, 앞서 보고된 음치 여부에 대한 비율은 신중히 접근해야 할 사항일 것이다. 즉 자가보고로 음치라 하였으나 실제 연구에서 접근하는 '음고 지각의 어려움이 아닌 본인 스스로 판단하기에 음 변별의 어려움은 없음에도 다른 사람보다 노래 능력에 소질 이 부족하다고 생각하여 스스로를 음치라 낙인찍는 등 다양한 주관적 근거가 반영된 결과의 가능성을 배제할 수 없다. 연구 참여자 중 본인 스스로 음치라 보고하고 DTT 수행력이 18점 이하로 음 변별의 어려움을 나타내었음에도 높은 시간적 처리 능력을 보인 사례가 있었으며, 이와는 반대로 자가로 음치라 보 고하지 않았으나 비정상적으로 연주되는 자극음에 대해 판단 
을 크게 어려워한 경우도 있었다. 이를 토대로 피검자의 변수 또한 DTT 및 결과 해석에 있어 신중하게 고려되어야 할 사항 일 것으로 결론 지을 수 있다.

음치 성인의 시간적 처리 능력을 알아본 결과 FPT, DPT의 허밍과 구어 반응 조건에서 귀 간 수행력 차이가 나타나지 않 았다. 오른손잡이의 경우 주로 우반구의 청각피질 영역에서 비 구어적인 정보, 좌반구에서 구어적인 정보의 처리를 담당하는 데 양이에 독립적으로 제시되는 서로 다른 높낮이의 주파수 및 서로 다른 길이의 음은 반응 방식에 따라 서로 다른 반구 간 처 리 과정을 요구한다. 즉 들은 음을 따라하는 허밍 반응의 경우 우반구 청각피질의 온전함을 요구하는 반면 들은 음의 높낮이 를 구어로 명명하도록 요청될 경우 좌반구의 온전함을 요구한 다. 이러한 처리 과정에 있어 제시되는 쪽의 귀에 따라 반구 간 구어/비구어적 정보를 전달하기 위해 뇌량의 중재 역할이 요구 된다. 따라서 시간적 순서화 능력을 확인하는 검사는 반구의 독립적/상호적 청각 정보 교환 능력에 대한 깊이 있는 정보를 제공한다. 본 연구에서 나타난 결과로 보았을 때 음치 성인에게 서 우반구의 청각 정보의 시간적 순서화 처리 능력에 결함이 없 는 것으로 결론 지을 수 있음을 시사한다.

본 연구 결과 FPT의 허밍과 구어 반응 조건에서 모두 음치 그 룹에서 유의하게 낮은 수행력을 나타내었는데, 이는 관련 선행 연구의 결과와 일치함을 보였다(Ishii et al., 2006; Jones et al., 2009). 그러나 같은 시간적 순서화 능력을 평가한다는 점에서 그 룹 간 DPT 수행력의 통계적 차이가 나타나지 않았다는 점은 이 전에 보고된 음치의 시간적 순서화 능력 결함(Ishii et al., 2006; Jones et al., 2009)의 보고와 반대되는 결과이다. 즉 본 연구의 통계결과를 고려해 볼 때 DPT에서 또한 대조군과 유의미한 차 이가 나타났음을 보고한 Jones et al.(2009)의 연구와는 달리 본 연구결과에서는 유의미한 차이가 나타나지 않아 이전의 연구에 서 노화변인이 시간적 처리 능력에 영향을 주었을 것으로 생각 된다. 따라서 본 연구를 토대로 음치의 시간적 처리 능력에는 문 제가 없는 것으로 결론 지을 수 있으며, FPT에서의 허밍과 구어 조건에서의 낮은 수행력은 시간적 처리 능력의 결함에서 기인된 것이 아닌 낮은 음고 변별 능력으로 인해 수행력에 영향을 미친 것으로 해석될 수 있다. 이는 임상에서 음치를 대상으로 시간적 순서화 범주의 검사를 시행할 때 FPT와 달리 개인의 낮은 음고 처리 능력과는 상관없이 사용될 수 있는 DPT를 채택할 필요성 이 요구됨을 시사한다.

시간적 분석 능력을 알아보기 위해 GIN 검사를 실시한 결과 $\mathrm{TDG}$ 에서 간격역치가 오른쪽이 왼쪽보다 유의미하게 높은 것 으로 나타났다. 그럼에도 $6 \mathrm{msec}$ 내의 정상 역치 범위(Musiek et al., 2005)에 속하는 수행력을 나타내었으므로, 음치 성인의 시간적 분석 능력에 결함이 없을 가능성이 높은 것으로 생각된
다. 또한 이와 같은 결과는 이전 선행연구들에서 보고하는 바 와 맥락을 같이함을 확인하였다(Ishii et al., 2006; Jones et al., 2009).

본 연구에서 음치 그룹의 FPT 수행력에서 높은 편차가 나타 남을 확인할 수 있었다. 실제로 자료 수집 과정 중 음치 성인에 게서 나타나는 수행 능력의 넓은 편차를 관찰할 수 있었다. 구 체적으로 $\mathrm{TDG}$ 에 속한 S3 피검자의 경우 FPT에서 허밍과 구 어 반응 조건에서 양이 모두 $100 \%$ 의 수행력을 나타내었으나, 같은 시간적 순서화 범주에 속한 DPT에서는 양이 모두 $40 \%$ 이하의 수행력을 나타내었으며(허밍 조건; Rt $40 \%$, Lt 46.7\%, 구어 조건; Rt $33.3 \%, \mathrm{Lt} 13.3 \%$, GIN 검사의 역치는 양이 모두 $8 \mathrm{msec}$ 로 정상 범위를 벗어난 수준을 보였다. 이와는 반대로 $\mathrm{S} 1$ 피검자의 경우 DPT에서 허밍과 구어 조건에서 양이 모두 $100 \%$ 의 수행력을 나타내었으나, FPT에서는 양이 모두 $35 \%$ 이하의 수행력을 나타내었으며(허밍 조건; Rt $33.3 \%$, Lt 6.67\%, 구어 조건; Rt $6.67 \%$, Lt 20\%), GIN 검사 역치는 양이 모두 정상 범 위를 나타내었다(Rt $6 \mathrm{msec}$, Lt $5 \mathrm{msec}$ ). 이와는 달리 세 검사 에서 모두 높은 수행력을 나타낸 대상자도 있었는데, S4의 경 우 FPT의 허밍 조건에서는 양이 $100 \%$ 의 수행력을, 구어 조건 에서는 Rt $86.7 \%$, Lt $80 \%$ 의 수행력을 보였으며, DPT에서는 양 이 모두 두 반응 조건에서 $100 \%$ 의 수행력과 GIN 검사 역치가 양이 모두 $5 \mathrm{sec}$ 로 나타나 정상 수행력을 나타내기도 하였다. 흥미롭게도 S10 피검자의 경우 DPT의 두 반응 조건에서 양이 모두 $100 \%$ 의 수행력과 $\mathrm{GIN}$ 검사에서 양이 모두 $5 \mathrm{sec}$ 의 역치 를 나타내었지만, FPT에서 제시되는 서로 다른 높낮이의 음이 모두 동일한 음으로 인지되어 변별 과제에 큰 어려움을 나타내 기도 하였다. 이와 같이 TDG에서의 넓은 수행력 분포는 앞선 선행연구(Jones et al., 2009)에서 밝힌 바와 같이 성인 음치 집 단에서 나타나는 넓은 분포의 시간적 처리 능력과 같은 맥락을 보였는데, 이는 개인별 음치의 정도 및 신경학적인 영향의 정도 가 개인별 능력의 차이와 그 특성에 반영된 결과로서 해석될 수 있다. 또한 정상적인 말초청력 및 인지, 언어 등 상위 능력 등 의 교란 요인(confounding factor)으로부터 영향을 받지 않았 음에도 TDG에서 나타낸 낮은 시간적 처리 능력은 중추청각처 리장애의 높은 가능성을 보이기 때문에 더욱 심도 있는 신경생 리학적 및 행동검사 결과를 통한 해석으로 그들의 일상생활에 서 보이는 듣기 어려움에 대한 이해가 필요할 것이다.

앞선 연구 결과들을 종합하여 볼 때 국내 20대 성인을 대상 으로 한 DTT는 음고 지각 능력의 어려움을 판별하고 확인함 에 유용할 것으로 생각되나, DTT를 통한 음치 판별에 있어 정 확도를 더욱 높이기 위해 추가적인 노력이 요구된다. 이와 동시 에 음치 그룹에게서 나타난 낮은 주파수 처리 능력은 낮은 음 지각 능력으로 기인된 것일 수 있으며, 더하여 대조군과 차이가 
없는 음 길이 인식 능력 및 정상 범위 시간적 분석 능력은 음치 성인의 시간적 처리 능력 결함을 반영하지 않을 수 있음을 시 사한다. 그러므로 그들을 대상으로 시간적 처리 검사를 진행할 때 FPT보다는 DPT를 선정하는 등 주의가 요구된다. 마지막으 로 음치 그룹 내 관찰된 개인별 다양한 처리 능력의 변수는 음 치에 대한 향후 구체적인 청각 처리적 능력에 대한 접근이 요구 됨을 시사하며, 향후 연구에서 다양한 음악 처리적 능력에 따 른 음치의 개인별 특성이 고려되었을 때 그들의 중추청각적 처 리 능력에 대한 더 깊은 이해가 가능할 것이다.

중심 단어 : 시간적 처리 능력·음치· Distorted Tunes Test (DTT).

\section{Ethical Statement}

All participants before the study were fully informed about the purpose and procedures of the study and voluntarily stated their intention to participate in the research and signed the consent form. This study was approved by the Institutional Review Board of the Hallym University (HIRB-2017-094).

\section{Acknowledgments}

The authors thank to the participants.

\section{Declaration of Conflicting Interests \\ There are no conflict interests.}

\section{Funding}

$\mathrm{N} / \mathrm{A}$

\section{Author Contributions}

All authors contributed equally to this work. K.Y. contributed to the design and implementation of the research, to the analysis of the results and to the writing of the manuscript. H.J. contributed to the direction of the research and to the final version of the manuscript. N.A. provided statistical analysis and critical revision. All authors also discussed the results and implications and contributed to the final manuscript.

\section{ORCID iDs}

Keonseok Yoon

https://orcid.org/0000-0002-1300-9405
Hyunsook Jang

https://orcid.org/0000-0001-5496-8218

\section{REFERENCES}

Albouy, P., Mattout, J., Bouet, R., Maby, E., Sanchez, G., Aguera, P. E., et al. (2013). Impaired pitch perception and memory in congenital amusia: The deficit starts in the auditory cortex. Brain, 136(Pt 5), 1639-1661.

ANSI. (1996). ANSI S3.6-1996: Specification for Audiometers. New York, NY: American National Standards Institute.

Bellis, T. J. \& Wilber, L. A. (2001). Effects of aging and gender on interhemispheric function. Journal of Speech, Language, and Hearing Research, 44(2), 246-263.

Braun, A., McArdle, J., Jones, J., Nechaev, V., Zalewski, C., Brewer, C., et al. (2008). Tune deafness: Processing melodic errors outside of conscious awareness as reflected by components of the auditory ERP. PLoS One, 3(6), e2349.

Drayna, D., Manichaikul, A., de Lange, M., Snieder, H., \& Spector, T. (2001).
Genetic correlates of musical pitch recognition in humans. Science, 291(5510), 1969-1972.

Hwang, S. R. (2008). A study on education for tone-deaf students through musicality program (Unpublished master's thesis). KongJu National University, Gongju.

Hyde, K. L., Zatorre, R. J., Griffiths, T. D., Lerch, J. P., \& Peretz, I. (2006). Morphometry of the amusic brain: A two-site study. Brain, 129(Pt 10), 2562-2570.

Ishii, C., Arashiro, P. M., \& Pereira, L. D. (2006). [Ordering and temporal resolution in professional singers and in well tuned and out of tune amateur singers]. Pró-Fono Revista de Atualização Científica, 18(3), 285292.

Jang, H., Lee, J., \& Yoo, S. (2008). Aging effects on frequency pattern recognition. Audiology and Speech Research, 4(1), 11-15.

Jones, J. L., Zalewski, C., Brewer, C., Lucker, J., \& Drayna, D. (2009). Widespread auditory deficits in tune deafness. Ear and Hearing, 30(1), 63-72.

Kalmus, H. \& Fry, D. B. (1980). On tune deafness (dysmelodia): Frequency, development, genetics and musical background. Annals of Human Genetics, 43(4), 369-382.

Kang, Y. W. (1994). Who is left-handed?: Measurement of handedness in Koreans. Korean Journal of Clinical Psychology, 13(1), 97-113.

Keith, R. W. (2000). Random Gap Detection Test. Auditec, Inc. Retrieved from https://auditec.com/.

Kown, M. R. (2007). A study on factor analysis of tone-deaf children and the methods to develop tone-controlling ability (Unpublished master's thesis). Daegu National University of Education, Daegu.

Lense, M. D., Shivers, C. M., \& Dykens, E. M. (2013). (A)musicality in Williams syndrome: Examining relationships among auditory perception, musical skill, and emotional responsiveness to music. Frontiers in Psychology, 4, 525.

Loui, P., Alsop, D., \& Schlaug, G. (2009). Tone deafness: A new disconnection syndrome? The Journal of Neuroscience, 29(33), 10215-10220.

Musiek, F. E. (1994). Frequency (pitch) and duration pattern tests. Journal of the American Academy of Audiology, 5(4), 265-268.

Musiek, F. E., Shinn, J. B., Jirsa, R., Bamiou, D. E., Baran, J. A., \& Zaida, E. (2005). GIN (Gaps-In-Noise) test performance in subjects with confirmed central auditory nervous system involvement. Ear and Hearing, 26(6), 608-618.

Peretz, I., Champod, A. S., \& Hyde, K. (2003). Varieties of musical disorders. The Montreal battery of evaluation of amusia. Annals of the New York Academy of Sciences, 999(1), 58-75.

Peretz, I., Cummings, S., \& Dubé, M. P. (2007). The genetics of congenital amusia (tone deafness): A family-aggregation study. The American Journal of Human Genetics, 81(3), 582-588.

Peretz, I. \& Vuvan, D. T. (2017). Prevalence of congenital amusia. European Journal of Human Genetics, 25(5), 625-630.

Provost, M. A. (2011). The prevalence of congenital amusia (Unpublished master's thesis). University of Montreal, Montreal.

Seung, Y., Kyong, J. S., Woo, S. H., Lee, B. T., \& Lee, K. M. (2005). Brain activation during music listening in individuals with or without prior music training. Neuroscience Research, 52(4), 323-329.

Sloboda, J. A., Wise, K. J., \& Peretz, I. (2005). Quantifying tone deafness in the general population. Annals of the New York Academy of Sciences, 1060, 255-261.

Son, J. H. (2003). The research about diagnosis and correction of tonedeafness (Unpublished master's thesis). Sookmyung Women's University, Seoul.

Tillmann, B., Schulze, K., \& Foxton, J. M. (2009). Congenital amusia: A short-term memory deficit for non-verbal, but not verbal sounds. Brain and Cognition, 71(3), 259-264. 